\title{
Digital Finance and Corporate Value: An Empirical Evidence from China
}

\author{
Boyu Yuan ${ }^{1, a, \dagger}$, Kangyu Zhao ${ }^{2, b, \dagger}$ and Xuekun Shen ${ }^{3, c, \dagger}$ \\ 1. School of Missouri State University springfield Mo 65897 America \\ 2. School of Hebei Science and Technology University, Shijiazhuang 050000, China \\ 3. School of Ottawa, Ottawa, K1N 6N5, Canada \\ a2534832049@qq.com, b1210928026@qq.com, c531371281@qq.com \\ tThese authors contributed equally
}

\begin{abstract}
Based on the Peking University Digital Financial Inclusive Index and SME data, this paper examines the relationship between digital financial development and corporate value. we found that the development of digital finance has a significant positive impact on corporate value. The heterogeneity analysis found that the development of digital finance has a greater impact on enterprises below the designated size, which reflects the inclusive nature of digital finance. This paper shows that digital finance is an important supplement to traditional financial services.
\end{abstract}

Keywords: Digital Finance; Corporate Value; Empirical Research.

\section{Introduction}

Under the background of the market-oriented competition, the operation and production of enterprises rely more and more on financial resources, while the development of financial resources, in turn, affects the competitiveness and operating performance of enterprises. As a market-oriented enterprise, it pays more attention to the allocation of the entire financial resources and provides financial resources to the enterprise through different channels, thereby promoting the overall business performance and market value of the enterprise. Especially under the influence of factors such as the epidemic and economic globalization, digital finance can take more advantage of logistics, information flow, and capital flow in financial resources under the background of deepening market uncertainty, in order to help improve the business performance and market of enterprises value. In the era of the digital economy where data has become a factor of production, digitalization has reconstructed the form, mode, and content of previous financial products or services. More and more enterprises are applying digital technology to the process of enterprise production, operation, and management.

However, there are currently few academic studies on the market value of digital finance for companies, especially empirical studies on digital finance.[1] In the short-term, consumption, investment, and net exports are usually referred to as the troikas that drive economic growth. Big data push into the characteristics of digital transformation [2]. More and more companies regard consumption, investment, and net exports as the three main channels through which digital financial inclusion affects economic growth. By using big data such as economic growth, consumption, investment, and net exports in various regions of China from 2011 to 2015, we can help realize more visualized financial data analysis. In 2015, the Bootstrap intermediary test program developed rapidly and was gradually used to analyze whether consumption, investment, and net exports played a significant role in the intermediary of digital financial inclusion in economic growth. The results show that in the national sample and the central region, the median utility of consumption and investment is significantly positive, and the mediating effect of net exports is not significant. In the western region, the mediating utility of consumption and investment is significantly positive, while the mediating utility of net exports is significantly negative. In the eastern region, only the mediating effect of consumption is significantly positive, while the mediating effect of investment and net exports is not significant. Among the three regions, digital financial inclusion has the greatest impact 
on economic growth in the western region, followed by the central region, and the eastern region has the least stimulating effect.

Today's human society is accelerating towards the digital age, finance to truly serve the real economy, for more real enterprises, we must be combined with digital technology. In this development process, the emerging financial industry, represented by digital finance, has been born. Digital finance is more accessible, has more product and service coverage and more sustainable than traditional finance, and is conducive to equal access to financial resources by all regions to promote economic progress [4]. Nowadays, all countries in the world pay great attention to digital finance, and as the leader of digital finance, China attaches great importance to the development and future trend of digital finance. The Financial Technology Development Plan (2019-2021) issued by the Central Bank of China in 2019 states that all sectors of the financial industry should "promote the efficient integration and development of finance and technology, pay attention to improving the application capacity and efficiency of digital science and technology, improve the operating mechanism of financial science and technology, and promote the sustainable development of fintech." It can be seen that promoting the high-quality development of digital finance has become an important construction content and development field of China's financial system. In recent years, many scholars have also researched digital finance and achieved some results. Studies have shown that digital financial development is conducive to promoting the upgrading of Chinese household consumption [5] and achieving high-quality economic development [6] For the micro-effect of digital finance, only a small number of scholars pay attention to the impact of digital finance on enterprise investment enterprise innovation ability [8], ignoring the impact of digital finance development on enterprise value. However, all business activities and development of enterprises are aimed at maximizing enterprise value at the source, and studies have shown that financial development can optimize enterprise asset allocation, ease corporate financing constraints, and realize enterprise valueadded [7].

The following parts are organized as follows: The second part is research design, introducing data source, model specification, and estimation method; the third part is empirical results; the $4^{\text {th }}$ part is heterogeneity analysis and $5^{\text {th }}$ part is the conclusion.

\section{Research Design}

\subsection{Data Source}

This article is based on the existing literature, fully refers to the research and analysis of digital finance by domestic and foreign researchers, and combines the past research results to construct an empirical analysis model. This article is used the Peking University Digital Financial Inclusion Index of China (PKU-DFIIC). This index was produced by a research team from the Institute of Digital Finance at Peking University and Ant Financial Services Group. HUANG Yiping, Director of the Institute of Digital Finance at Peking University, and LIANG Shidong, Vice President of Ant Financial Services Group serve as advisors of the research team. The members of the research team included GUO Feng, KONG Tao, WANG Jingyi, ZHANG Xun, CHENG Zhiyun, RUAN Fangyuan, SUN Tao and WANG Fang in stage I (2011-2015), and included GUO Feng, WANG Jingyi, CHENG Zhiyun, LI Yongguo, WANG Fang and WEI Aiyong in stage II (2016-2018). The research team also got much technical support from many colleagues of Peking University and Ant Financial Services Group. The Peking University Digital Financial Inclusion Index of China (PKU-DFIIC) involves coverage breadth, usage depth, and digitization level; usage depth involves sub-indexes such as payment, credit, insurance, credit, investment, and money funds. 31 provinces (and municipalities directly under the Central Government and autonomous regions, referred to as "provinces"), 337 cities above the prefecture-level (and regions, autonomous prefectures, alliances, etc., referred to as "cities"), and nearly 2,800 counties (and county-level cities, banners, municipal districts, etc., referred to as "counties"). The data of some regions are lacking, for example, Hong Kong SAR, Macao SAR, and Taiwan province. 2011-2018 for provincial level and prefecture-level, 2014-2018 for county- 
level from 2011 to 2018, some regions in China carried out reforms such as "setting up cities by withdrawing regions" and "changing counties (and county-level cities) into municipal districts", which adjusted the regional names and regionalism codes but did not affect the statistics of this index. The codes of prefecture-level cities in this index retained both versions of 2014 and 2018, while the county names and regionalism codes were based on the codes at the end of 2014 so that users can combine other economic and social data for analysis. In addition, the enterprise-level data comes from the CSMAR database.

\subsection{Model Design and Variable Definition}

This article mainly adopts the research method of empirical analysis, and based on reference to a large number of documents, proposes the influence mechanism of digital finance on enterprise value, and makes research hypotheses. At the same time, an empirical analysis model was constructed, and a large amount of relevant data was searched through databases such as Guotaian and wind, and then panel data of listed companies in China from 2011 to 2018 were obtained. At the same time, the digital finance data of various provinces and cities are obtained from the data of the Digital Finance Research Center of Peking University. We employed the following model to achieve our research objective:

$$
\mathrm{Q}_{\mathrm{i}, \mathrm{t}}=\beta_{0}+\beta_{1} * \text { digitizationlevel }_{\mathrm{i}, \mathrm{t}}+\beta_{2} * \operatorname{control}_{\mathrm{i}, \mathrm{t}}+\mu_{\mathrm{i}, \mathrm{t}}
$$

In the above formulas, $\mathrm{i}$ represents the listed company $\mathrm{i}=1,2,3, \ldots, \mathrm{n}, \mathrm{t}$ represents the year $\mathrm{t}=2011$, $2011, \ldots, 2018, \mu$ is the random disturbance term, and control is the control variable.

A regression model is constructed with Tobin's Q of listed companies in China as the core explanatory variable, and digital finance as the explanatory variable. The research object of this article is Chinese listed companies. The selected data include the data of 2,564 listed companies between 2011 and 2018. The data comes from the annual reports of major companies and the CSMAR database. The data of digital finance comes from the data of Peking University Digital Finance Research Center.[9]

In addition, this article also carried out a series of data processing during the data collection process. First, remove the sample of companies in the financial industry; second, remove the samples of companies that are ST and *ST; third, remove the samples with missing values for the variables; finally, this paper performs $1 \%$ bilateral tailing on the main continuous variables. In the end, 20506 sample data were obtained. The tool used in this article for data processing and analysis is Stata 15.1

\subsection{Descriptive Statistics}

Table 1. Descriptive Statistics

\begin{tabular}{|c|c|c|c|c|c|}
\hline Variable & Obs & Mean & Std. Dev. & Min & Max \\
\hline lev & 20,182 & 41.99098 & 21.30241 & 4.8457 & 92.0262 \\
\hline roa & 20,182 & 6.24064 & 6.243097 & -16.7851 & 26.1217 \\
\hline top1 & 20,182 & 35.23857 & 14.94509 & 8.77 & 74.89 \\
\hline age & 20,182 & 9.440293 & 7.16826 & 0 & 24 \\
\hline own & 20,182 & 0.4053117 & 0.4909644 & 0 & 1 \\
\hline Q & 20,182 & 2.124846 & 1.339399 & 0.925416 & 8.776462 \\
\hline digitization level & 20,182 & 276.0098 & 113.9903 & 15.71 & 440.2605 \\
\hline cinten & 20,182 & 21.73393 & 16.61718 & 0.0007858 & 97.09213 \\
\hline Insize & 20,182 & 22.08673 & 1.333495 & 16.16134 & 28.51996 \\
\hline
\end{tabular}


The following table shows the descriptive statistical results of each variable. It can be seen that the maximum value of the explained variable Tobin $Q$ is 1056.725 , the minimum value is 0.657 , the standard deviation is 11.48 , and the average value is 2.416 , indicating that the Tobin Q data of listed companies are quite different. The minimum value of the explanatory variable digitization level variable is 7.58 , the maximum value is 453.66 , the mean value is 275.918 , and the standard deviation is 114.246, indicating that there are large differences in the degree of digital finance development in different provinces in China. The descriptive analysis results of the explained variables and the explanatory variables show that the Tobin Q of listed companies and the digital financial data of various provinces and cities are quite different, which is consistent with the previous analysis of the current situation.

\section{Regression Analysis of Digital Finance to Corporate Value}

To demonstrate in detail, the impact of the related variables of the impact mechanism of digital finance on corporate value, this paper constructs a multiple regression model with corporate valuerelated indicators as the explained variables and digital financial indexes as the explanatory variables. The regression model is mainly to investigate the specific impact of digital finance on the value of the enterprise when other variables remain unchanged. The specific regression results are shown in the following table (Model 1, Model 2, Model 3, and Model 4). Among them, the implementation model is the analysis of the regression results of the specific impact of digital finance on the value of the enterprise under the hybrid regression. The second model is the mixed regression analysis of the specific impact of digital finance on the value of the enterprise under the control variable conditions. Model three is the regression analysis of the specific impact of digital finance on corporate value under fixed effects regression. The fourth model is the regression analysis of the fixed effects of the specific impact of digital finance on the value of the enterprise under the condition of controlled variables.

The first is the analysis of model one. From the table below, we can see that in the regression results of Model 1, R2 adjusted to 0.032 indicates that appropriate goodwill is good, and the model's interpretation of each explanatory variable is statistically significant. Looking at the results of the model, we can see that the digitization level coefficient is 0.002 , and the negative hypothesis is negative at the $1 \%$ confidence level, indicating that the digitization level of digital finance has a significant positive correlation with enterprise value Q. In other words, for every $1 \%$ increase in the digitization of digital finance, the enterprise value $Q$ will increase by $0.002 \%$. Secondly, the adjusted $\mathrm{R} 2$ in the regression results of model two is 0.275 , which indicates that the explanatory power of each explanatory variable in the model has good applicability and statistical significance. Looking at the model results, we can find that the digital level coefficient is 0.003 , and the null hypothesis is negative at the $1 \%$ confidence level, indicating that the digital level of digital finance has a beneficial effect on the value of the enterprise Q. That is, for every $1 \%$ increase in the digitization of digital finance, the business value Q increases by $0.003 \%$. Third, according to the survey data, it can be seen that the adjusted R2 in the three regression results of the model is 0.078 , indicating that the applicability is good, and the explanatory power of each explanatory variable in the model is statistically significant. Observing the results of the model, we can find that the digital level coefficient is 0.002 , and the negative hypothesis is $1 \%$ confidence level. This result shows that the digital level of digital finance can promote the growth of enterprise value $\mathrm{Q}$. That is, for every $1 \%$ increase in the digitization level of digital finance, the enterprise value $Q$ will increase by $0.002 \%$. In the last model, the adjusted R2 in the regression results of model (4) is 0.163 , indicating that the model has a good fit for the explanatory variables of each explanatory variable and is statistically significant. Looking at the results of the model, we can find that the digital level coefficient is 0.003 , and the negative hypothesis is a $1 \%$ confidence level, indicating that the digital level of digital finance has increased the value of the enterprise $\mathrm{Q}$. That is, for every $1 \%$ increase in the number of financial digitization, the business value $\mathrm{Q}$ will increase by $0.003 \%$. 
Table 2. Regression results of the impact of digital finance on corporate value

\begin{tabular}{|c|c|c|c|c|}
\hline & $(1)$ & $(2)$ & $(3)$ & $(4)$ \\
\hline VARIABLES & $\mathrm{Q}$ & $\mathrm{Q}$ & $\mathrm{Q}$ & $\mathrm{Q}$ \\
\hline digitization level & $0.002^{* * *}$ & $0.003^{* * *}$ & $0.002^{* * *}$ & $0.004^{* * *}$ \\
\hline Ln size & $(0.000)$ & $(0.000)$ & $(0.000)$ & $(0.000)$ \\
\hline lev & & $-0.476^{* * *}$ & & $-0.587^{* * *}$ \\
\hline & & $(0.025)$ & & $(0.045)$ \\
\hline ROA & & -0.001 & & $(0.001)$ \\
\hline Cinten & & $(0.001)$ & & $0.040^{* * *}$ \\
\hline & & $0.034^{* * *}$ & & $(0.003)$ \\
\hline top1 & $(0.003)$ & & $-0.007^{* * *}$ \\
\hline & & $-0.006^{* * *}$ & & $(0.002)$ \\
\hline age & & $(0.001)$ & & $-0.014^{* * *}$ \\
\hline & & $-0.003^{* * *}$ & & $0.002)$ \\
\hline own & & $(0.001)$ & & 0.010 \\
\hline Constant & & $\left(0.045^{* * *}\right.$ & & $0.010)$ \\
\hline & & -0.030 & & \\
\hline & $1.527^{* * *}$ & $(0.038)$ & & $14.062^{* * *}$ \\
\hline Observations & $(0.025)$ & $(0.490)$ & $(0.024)$ & $(0.924)$ \\
\hline R-squared & 20,182 & 20,182 & 15,760 & 15,760 \\
\hline Number of id & 0.034 & 0.275 & 0.090 & 0.181 \\
\hline & & & 1,970 & 1,970 \\
\hline
\end{tabular}

\section{Analysis of the Heterogeneity of Digital Finance to Corporate Value}

Table 3. The heterogeneous results of digital finance on corporate value

\begin{tabular}{|c|c|c|c|c|}
\hline & (1) & (2) & (3) & (4) \\
\hline VARIABLES & $\mathrm{Q}$ & $\mathrm{Q}$ & Q & Q \\
\hline \multirow[t]{2}{*}{ Dummy } & $-0.359 * * *$ & $0.437 * * *$ & $0.648 * * *$ & $0.890 * * *$ \\
\hline & $(0.045)$ & $(0.050)$ & $(0.054)$ & $(0.051)$ \\
\hline \multirow[t]{2}{*}{ Dummy \# digitization level } & $-0.002 * * *$ & $-0.002 * * *$ & $-0.004 * * *$ & $-0.003 * * *$ \\
\hline & $(0.000)$ & $(0.000)$ & $(0.000)$ & $(0.000)$ \\
\hline \multirow[t]{2}{*}{ digitization level } & $0.003^{* * *}$ & $0.004 * * *$ & $0.005 * * *$ & $0.005^{* * *}$ \\
\hline & $(0.000)$ & $(0.000)$ & $(0.000)$ & $(0.000)$ \\
\hline \multirow[t]{2}{*}{ Ln size } & & $-0.434 * * *$ & & $-0.563 * * *$ \\
\hline & & $(0.030)$ & & $(0.051)$ \\
\hline \multirow[t]{2}{*}{ lev } & & -0.001 & & $0.009 * * *$ \\
\hline & & $(0.001)$ & & $(0.001)$ \\
\hline \multirow{2}{*}{ ROA } & & $0.034 * * *$ & & $0.039 * * *$ \\
\hline & & $(0.003)$ & & $(0.003)$ \\
\hline \multirow[t]{2}{*}{ Cinten } & & $-0.006 * * *$ & & $-0.007 * * *$ \\
\hline & & $(0.001)$ & & $(0.002)$ \\
\hline \multirow[t]{2}{*}{ top1 } & & $-0.004 * * *$ & & $-0.013 * * *$ \\
\hline & & $(0.001)$ & & $(0.002)$ \\
\hline \multirow[t]{2}{*}{ age } & & $0.047 * * *$ & & $0.023^{* *}$ \\
\hline & & $(0.003)$ & & $(0.010)$ \\
\hline \multirow[t]{2}{*}{ own } & & -0.037 & & \\
\hline & & $(0.038)$ & & \\
\hline \multirow[t]{2}{*}{ Constant } & $1.627 * * *$ & $10.512 * * *$ & $1.161 * * *$ & $13.085^{* * *}$ \\
\hline & $(0.037)$ & $(0.606)$ & $(0.039)$ & $(1.060)$ \\
\hline Observations & 20,182 & 20,182 & 15,760 & 15,760 \\
\hline R-squared & 0.139 & 0.284 & 0.150 & 0.224 \\
\hline Number of id & & & 1,970 & 1,970 \\
\hline
\end{tabular}


To more accurately characterize the impact of digital finance on corporate value, this article will further conduct an empirical analysis of digital finance on corporate value among companies of different sizes. Among them, companies with total assets in the median and above will be regarded as large companies. The rest are defined as small and medium enterprises. Heterogeneity essentially means difference and difference. It can be either on the individual level or on the group level. Therefore, this paper uses statistical analysis methods from the simplest t-test, analysis of variance to more complex multiple regression analysis to make the data more reasonable and scientific. In actual research, although often all individuals in a sample may not have the same set of parameter values, it is still often seen that the data is analyzed as if it were obtained from a single population. Many researchers often realize that a population may be heterogeneous, being a mixture of multiple different sub-populations. For this reason, this paper attempts to relax the overall assumption of homogeneity as much as possible in the model setting and selection, to obtain a more reasonable understanding or make empirical tests on more complex theoretical hypotheses.

From the following table, we can get that after adding the dummy variable $d$ of large enterprises, the explanatory variable digitization level has a positive coefficient for $Q$, and at the same time reject the null hypothesis at the $1 \%$ significance level. The impact of digital finance development on large enterprises (Subject to the fourth column) $=0.005-0.003=0.002$, the impact on SMEs is 0.005, indicating that the development of digital finance has a greater positive impact on the value of SMEs.

\section{Conclusion}

This article mainly takes big data innovation as the breakthrough point and takes Chinese listed companies as the research object to analyze the heterogeneity test of enterprise scale. In the end, it will further demonstrate the influence of digital finance and the nature of the enterprise on the value of the enterprise. And using the panel data of China's listed companies from 2011 to 2018, the fixedeffect model is used to analyze the panel data, and it deeply reveals the impact of big data and digital finance on China's listed companies. To demonstrate in detail the influence of the related variables of the impact mechanism of digital finance on corporate value, this paper constructs a multiple regression model with corporate value-related indicators as the explained variables and the digital financial index as the explanatory variables. Digital finance plays a significant positive role in promoting enterprise innovation, indicating that the development of digital finance can ease the financing of local enterprises Capital constraint plays a positive role in promoting enterprise innovation. In the traditional financial model, financing constraints restrict the technological innovation input of SMEs, digital finance can ease the financing constraints of enterprises, and then promote the technological innovation of SMEs. The study found that: (1) Digital finance has a promoting effect on the value of listed companies (2) The development of digital finance has a greater positive impact on the value of SMEs.

\section{References}

[1] Guo Baihong. Analysis of the Impact of Internet Finance on SME Financing- Comparison with Traditional Finance.

[2] Wei Yanqiu, Huang Xu, Zhang Wei. Digital Transformation of Commercial Banks in the Age of Big Data.

[3] Li Kemu. Innovation and Risk in Internet Finance Cao Fengqi. The Challenge of Internet Finance to Traditional Finance.

[4] Zhang Xun, Wan Guanghua, Zhang Jiajia, He Zongxuan. 2019. Digital Economy, Inclusive Finance and Inclusive Growth. Economic Research (8): 71-86.

[5] Yang Weiming, Su Lin, Sun Ruili, Yuan Weipeng.2021. Has digital finance contributed to the upgrade of consumption? --evidence based on panel data. International Financial Research (4): 13-22.

[6] Teng Lei, Madeko. 2020. Can digital finance promote high-quality development? [J]. Statistical Research (11): 80-92. 
[7] Syllar. 2002. Financial system sand economic modernization [J]. Journal of Economic History (2): 277 292.

[8] Tang Song, Wu Xuchuan, Zhu Jia. 2020. Digital Finance and Enterprise Technology Innovation -Structural Characteristics, Mechanism Identification and Effect Differences under Financial Supervision. Managing the World (5): 52-66.

[9] Li Xiaoling, Cui Shulin, Lai Xiaobing. 2020. whether digital finance can enhance the value of listed enterprises? Analysis and empirical test of --theoretical mechanism. Modern Finance (Journal of Tianjin University of Finance and Economics) (9): 83-95.

[10] Nie XIUhua, research on the path and heterogeneity of digital finance promoting smes' technological innovation [J]. Western Forum 2020-06-24.

[11] Jia Junsheng, Digital Finance, Executive background and enterprise Innovation: Empirical evidence from SMES and GEM Listed companies. Finance and Trade Research 2021-02-15. 